 \\ Original Article
}

\section{Analisis karier tentang pengembangan profesi bagi guru jenjang pendidikan anak usia dini}

\author{
Yusuf Maulana Prawata ${ }^{\left.1^{*}\right)}$, Lara Fridani ${ }^{2}$, \& Happy Karlina Marjo ${ }^{3}$ \\ Universitas Negeri Jakarta ${ }^{123}$ \\ *) Alamat korespondensi: Jl. Bumi Sakinah IV B5/20, Bekasi, 17520, Indonesia; E-mail: yusufmaulanap@gmail.com
}

Article History:

Received: 27/06/2021;

Revised: 30/06/2021;

Accepted: 30/06/2021;

Published: 30/06/2021.

How to cite:

Prawata, Y.M., Fridani, L., \&

Marjo, H.K. (2021). Analisis

karier tentang pengembangan profesi bagi guru jenjang pendidikan anak usia dini.

Teraputik: Jurnal Bimbingan dan

Konseling, 5(1), pp. 179-184. DOI: 10.26539/teraputik.51672

\footnotetext{
(c) (i) This is an open access article distributed under the Creative Commons 4.0 Attribution License, which permits unrestricted use, distribution, and reproduction in any medium provided the original work is properly cited. () 2021, Prawata, Y.M., Fridani, L., \& Marjo, H.K.(s).
}

\begin{abstract}
Abstrak: Penelitian ini bertujuan untuk mengetahui pengembangan profesi guru pada jenjang anak usia dini melalui aspek teori perkembangan karier Super pada fase establishment. Penelitian ini dilatarbelakangi sebuah fenomena bahwa guru pada jenjang pendidikan anak usia dini belum sepenuhnya memenuhi kualifikasi guru profesional. Metode penelitian yang digunakan adalah deskriptif kualitatif dengan pengambilan data melalui wawancara tidak terstruktur dan Focus Group Disscusion. Penelitian diikuti oleh tujuh orang guru. Hasil penelitian menunjukkan bahwa partisipan memulai profesi sebagai guru dengan pendidikan yang belum menunjang. kesimpulan dari penelitian adalah dengan berbagai keterbatasan, namun guru anak usia dini tetap komitmen berkarier sebagai guru dan berupaya mengembangkan kariernya. Dunia pendidikan anak adalah pembelajaran terbaik bagi para guru, kebahagiaan menyaksikan perkembangan anak dan mendapatkan pengalaman pekerjaan dapat menepikan persoalan salary.
\end{abstract}

Kata Kunci: Karier, Perkembangan, Profesi, Guru PAUD

Abstract: This study aims to find out the development of the teacher profession at an early childhood level through aspects of super career development theory in the establishment phase. This research is motivated by a phenomenon that teachers at the early childhood education level have not fully qualified professional teachers. The research method used is descriptive qualitative with data retrieval through unstructured interviews and Focus Group Disscusion. The study was attended by seven teachers. The results showed that participants started the profession as teachers with an education that has not been supported. the conclusion of the research is with various limitations, but early childhood teachers remain committed to a career as teachers and strive to develop their careers. The world of children's education is the best learning for teachers, the happiness of watching children's development and getting work experience can solve problems salary.

Keywords: Career, Development, Profession, Early Child Teacher

\section{Pendahuluan}

Guru adalah tenaga profesional dan memiliki peran sentral dalam mewujudkan tujuan pendidikan nasional yakni mencerdaskan kehidupan bangsa, maupun mensukseskan visi pendidikan pada unit kerja tempat guru berada. Meski kerap mengalami penyesuaian peraturan sebagai landasan kinerja, namun guru tetaplah sosok yang diyakini memiliki kapasitas adaptif yang mumpuni, dan dapat menyesuaikan dengan berbagai tuntutan serta menjadikannya sebagai sebuah tantangan profesi.

Umumnya seseorang memilih profesi menjadi guru Anak Usia Dini (AUD) dalam kondisi belum memiliki kualifikasi profesional. Ini adalah fenomena tersendiri bila dibanding dengan jenjang pendidikan lainnya. Padahal pendidikan AUD adalah dasar pijakan bagi individu, momentum anak mengawali aktivitas pembelajaran dalam lingkup formal, seyogyanya masa awal pengenalan akan dunia belajar di isi oleh tenaga yang profesional sekaligus peletak pilar pendidikan bagi anak. Fenomena lainnya adalah lulusan sarjana belum tentu memilih berkarier sebagai guru AUD. Sikap demikian didasari pertimbangan rasional, seperti persoalan salary maupun jenjang karier. Secara umum, usia bagi seorang sarjana berada pada akhir tahap eksplorasi (salah satu fase dalam teori perkembangan karier Super), sebuah kondisi ketika 
individu bisa saja memilih pekerjaan yang lebih menjanjikan dalam hal finansial maupun prospek karier. Pengecualian tentu bila ada faktor komitmen untuk tetap menjadi guru AUD dan berusaha mengembangkan karier melalui peluang yang ada. Studi Efrida Ida (2020) yang berjudul pengembangan profesional guru pendidikan anak usia dini (studi pada TKK Ade Irma Kabupaten Ngada), salah satu hasilnyanya adalah kondisi guru dilihat dari kualifikasi pendidikan belum memenuhi standar, sejumlah dua orang guru lulusan SMA dan SMK. Ini adalah tantangan tersendiri, bagaimanapun guru AUD kelak harus di isi oleh lulusan yang sesuai tuntutan profesional.

Tujuan pengembangan profesional bagi guru Anak Usia Dini (AUD) antara lain pengetahuan tentang isi pelajaran, pengetahuan tentang pendidikan, pengetahuan tentang profesional, dan kualitas profesional (Morisson 2012: 4). Mengingat undang-undang No 14 Tahun 2005, menyebutkan bahwa kualifikasi pendidikan minimum D4/S1) serta memiliki sertifikat pendidik merupakan bukti formal guru sebagai tenaga profesional. Profesional berkaitan dengan profesi yang dijalani, profesi itu sendiri merupakan pekerjaan. Dalam cakupan pekerjaan yang dilakukan oleh seorang individu selama hidupnya maka istilah karier dapat digunakan, Menurut Gibson dkk (1995: 305) karier adalah rangkaian sikap dan perilaku yang berkaitan dengan pengalaman dan aktivitas kerja selama rentang waktu kehidupan seseorang dan rangkaian aktivitas kerja yang terus berkelanjutan.

\section{Metode}

Penelitian menggunakan metode deskriptif kualitatif. Adapun partisipan penelitian sebanyak tujuh orang guru AUD. Pengambilan data awal melalui wawancara tidak terstruktur secara personal, informasi yang digali adalah menyangkut data-data personal. Tahapan selanjutnya adalah menggunakan wawancara berkelompok melalui metode Focus Group Discussion (FGD) dengan pelaksanaannya melalui platform zoom. Terhitung sejak study pendahuluan, penelitian berlangsung selama satu semester. Instrumen penunjang pertanyaan ketika wawancara kelompok berisi salah satu tahapan dari teori perkembangan karier Super, yaitu fase establishment, yang berada dalam rentang usia 25 - 44 tahun, usia partisipan berada dalam rentang ini. Aspek-aspek dari tahap establishment antara lain : komitmen, stabilisasi, konolidasi, frustasi, dan kemajuan.

\section{Hasil dan Diskusi}

Hasil penelitian menunjukkan bahwa keseluruhan partisipan tidak menjadikan guru AUD sebagai pilihan karier pertama. Keseluruhan partisipan juga memulai karier sebagai guru dengan latar belakang pendidikan tidak sesuai kriteria guru profesional. Ketika menjalani profesi guru AUD, partisipan melanjutkan studi dan akhirnya partisipan memiliki latar belakang pendidikan sarjana dan sebidang,.

Dari keseluruhan partisipan hanya satu partisipan yang telah memilii sertifikat pendidik. Mengacu pada ketentuan yang ada, berarti hanya satu yang memiliki kualifikasi sebagai guru profesional. Pada aspek frustasi keseluruhan tidak mengalami frustasi secara khusus menjalani profesi sebagai guru AUD, namun mengalami hal yang lain dengan bahasa berbeda, seperti tekanan bathin, sebal, merasa minder, jengkel, sebal. Partisipan menjadikan ukuran kata-kata yang tersampaikan untuk menggambarkan tiga hal yaitu imbalan, anggapan kerabat, dan menghadapi anak-anak.

Menariknya dari berbagai keterbatasan yang ada pada profesi ini, Keseluruhan partisipan berkomitmen terhadap profesi sebagai guiru AUD. Keseluruhan partisipan juga sepakat untuk tetap menjadi guru AUD, dan terus meningkatkan diri dengan belajar agar memiliki kemampuan dan keterampilan yang lebih baik dalam menangani anak. Mengingat teknologi dan pendidikan senantiasa berubah disetiap jaman, jadi setiap guru harus mengikuti perkembangan yang ada.

Membahas aspek kemajuan dari teori perkembangan karier Super, dalam kaitannya dengan upaya meningkatkan kapasitas diri, partisipan memiliki tanggapan bahwa ia ingin terus 
belajar dan jika ada program pemerintah yang berkaitan dengan pengembangan profesi maka akan diikuti. pada dasarnya lingkungan tempat partisipan berada membuka peluang bagi guru untuk mengembangkan kariernya, setidaknya melalui tahapan hirarki karier dalam struktural.

Komitmen dalam hal karier menjadi salah satu karakteristik pada teori perkembangan karier Super, dalam konsep Super, pilihan karier adalah mengenai kecocokan (matching). Memilih pekerjaan bukan peristiwa yang sekali terjadi dalam kehidupan seseorang. Karier bagaikan potongan teka-teki yang harus dicarikan kecocokan gambar sebelum bertemu situasi gambar tersusun utuh. Proses gambar menjadi sempurna bagaikan seseorang bertemu pilihan yang tepat. momentum pencocokan gambar bisa terjadi dikala seseorang mengenyam pendidikan tinggi, lalu ketika lulus ia baru mendapatkan kondisi gambar utuh lalu memutuskan berkarier sebagai guru anak usia dini.

Pengembangan karier merupakan bagian yang ditempuh para partisipan. Walaupun dengan titik pencapaian yang berbeda, irisan dari kesemuanya adalah kestabilan kondisi diri dan kondisi pekerjaan, mengingat sebagian besar partisipan belum memiliki sertifikat pendidik. Pijakan dari pengembangan karier bagi partisipan adalah komitmen yang tinggi terhadap profesi, terdapat dua partisipan yang sebelum mengajar berprofesi dibidang lain, lalu memutuskan untuk tetap menjadi guru. keseluruhan partisipam memiliki kemantapan yang sama untuk tetap menjadi guru. pertimbangan pribadi yang rasional pada akhirnya mengalahkan faktor finansial. Pertimbangan pribadi yang dimaksud antara lain : waktu untuk keluarga, durasi pekerjaan yang tidak panjang, aktivitas yang fleksibel, ilmu dan pengalaman yang diserap dalam pekerjaan akan sangat berharga bagi pendidikan anak dikeluarga. Partisipan memiliki keyakinan tinggi akan profesi yang dijalani dan umumnya tidak merasa khawatir akan masa depannya.

Menjadi guru AUD dianggap memiliki kemuliaan tersendiri, partisipan merasa bahwa menanamkan pengajaran pada para generasi belia, bagaikan menanam kebaikan dan keberkahan. Sisi spiritual begitu kuat tertanam dalam benak para partisipan, keyakinan tinggi kepada Sang Maha Pencipta akan rejeki yang didapatkan jauh melebihi kekhawatiran akan kondisi finansial yang dialami. Menyangkut hal yang berhubungan dengan keuangan, sangat dipahami, mengingat hampir semua partisipan telah berkeluarga, itu bermakna bahwa penunjang utama kebutuhan keluarga bukan berada pada partisipan. Salah satu partisipan yang belum berkeluarga masih memiliki rasa khawatir, karena belum memiliki pendamping, namun secara tersirat kekhawatiran tersebut lebih bertitik berat terhadap dukungan yang akan diberikan dan bukan kepada faktor finansial, mengingat partisipan berada disekolah dengan salary yang baik.

Keseluruhan partisipan memutuskan untuk berkarier sebagai guru AUD karena memang mencintai anak dan menyukai dunia anak. Kecintaan terhadap profesi ini mengabaikan kekurangan-kekurangan yang terjadi dikala melakukan aktivitas pekerjaan. Kreativitas adalah solusi jangka pendek dan berdampak besar bagi guru ketika menghadapi kekurangan fasilitas penunjang pembelajaran. Fenomena ketidakpahaman guru dalam menangani anak pada awal bekerja, menjadikannya motivasi kuat untuk mempelajari mengenai penunjang pembelajaran anak. Dengan dasar cinta anak partisipan merasa butuh untuk belajar kembali. Dalam kondisi nyata, saluran-saluran pembelajaran partisipan berasal dari kegiatan-kegiatan yang diikuti seperti seminar-seminar, maupun pelatihan-pelatihan melalui wadah organisasi profesi yang diikuti partisipan. Upaya pengembangan diri yang dilakukan partisipan bermuara pada satu tekad, yaitu ingin melakukan pekerjaan jauh lebih baik dari sebelumnya. Karakteristik asli guru adalah pembelajar sejati dan senantiasa siap dengan berbagai perubahan untuk kebaikan.

Seperti halnya profesi lain, guru juga memiliki tantangan-tantangan pekerjaan. Tantangan kerja partisipan mayoritas berada diwaktu awal memulai pekerjaan sebagai guru. masa-masa adaptasi adalah bagian yang cukup sulit bagi partisipan, difase awal partisipan merasakan kebingungan menghadapi tingkah pola anak dan bagaimana harus menanganinya. Dengan dasar keilmuan yang belum menunjang disaat memulai pekerjaan, partisipan dituntut belajar dengan tingkat akselerasi tinggi, mengingat anak identik dengan bergerak. Fokus partisipan dalam pembenahan diri ini seringkali mengabaikan kebutuhan-kebutuhan partisipan itu sendiri. Dalam satu titik partisipan merasa tak memperdulikan apa yang didapat, dan mendahulukan penanganan dan pengembangan anak. Prinsip mendidik anak bagai mengukir diatas batu begitu melekat dalam benak partisipan. Seiring durasi pekerjaan partisipan banyak mengikuti 
pembelajaran dalam rangka meningkatkan keterampilan pembelajaran dan penanganan anak, hasil dari itu adalah penanganan terhadap anak jauh lebih baik menurut pandangan partisipan.

Belajar dikala bekerja bukanlah hal yang mudah, ini dirasakan ketika tuntutan profesi mengharuskan guru memiliki kualifikasi pendidikan standar pendidik. Partisipan berupaya keras menyisihkan apa yang didapat untuk biaya melanjutkan pendidikan. Biaya dan berbagi perhatian antara bekerja dan kuliah memiliki konsekuensi yang tidak ringan, namun dengan semangat menggapai menuntut ilmu dan menggapai kualifikasi membawa energi tambahan bagi partisipan ketika memutuskan kuliah di usia bekerja. Bagi partisipan pengetahuan dan keterampilan adalah hal yang harus dimiliki, utamanya untuk menunjang pekerjaannya. Persoalan diklasifikasikan sebagai guru profesional itu menjadi hal berbeda dipemikiran selanjutnya.

Salah satu hasil dari penelitian adalah menyangkut upaya diri dalam mengembangkan karier, partispan berusaha menggapainya , meskipun tidak sekuat komitmen untuk tetap menjadi guru. bagi partisipan peningkatan karier saat ini adalah menggapai kualifikasi pendidik profesional, dan ini berkorelasi terhadap banyak lini : finansial, prospek karier selanjutnya, dan ketenangan dalam menjalani pekerjaan. Di sisi lain partisipan mengungkapkan bahwa konsekuensi berat akan didapatkan jika karier berkembang, utamanya waktu, dan beban amanah yang meningkat, karena menjadi guru dilandasi karena ingin memiliki keluangan waktu untuk keluarga. Adalah hal yang lumrah, membahas hal yang belum berada dalam ranah yang dipijak, akan membuat individu belum memiliki bayangan tersendiri, fantasi yang berkembang dilandasi oleh informasi yang didapat secara pribadi tentang hal yang harus dijalankan.

Apresiasi positif layak disematkan kepada partisipan, menyangkut komitmen untuk tetap berprofesi sebagai guru AUD. Asumsi masyarakat mengenai guru anak usia dini tercermin dalam pandangan partisipan dimana stigma profesi yang hanya sebatas guru TK, atau profesi dengan pengasilan minim, awalnya menggoyahkan pendirian. Kedewasaan berkarier, salah satunya ditentukan dari kematangan berfikir, pada akhirnya membawa partisipan untuk bisa menerima kenyataan hidup bahwa partisipan berprofesi sebagai guru anak usia dini karena mencintai anak, agar tersedia waktu untuk keluarga, karena untuk kebermanfaatan. Kekuatan diri dan cara menyikapi keadaan partisipan adalah hal positif dari penelitian ini. Penguat dari ini adalah ketika salah satu partisipan mengatakan bahwa guru harus siap menyesuaikan diri, mengingat pada setiap zaman tekologi dan pendidikan berubah-ubah. Seketika peneliti mengkomparasi dengan pandangan agama yang menyebutkan "didiklah anak-anakmu sesuai zamannya."

Penelitian ini akan membawa dampak besar jika lebih menggali informasi dari partisipan yang lebih maksimal lagi, semisal menggunakan metode eksperimen melalui bimbingan kelompok. Apa yang tergambar dalam penelitian ini bisa menjadi bahan untuk melakukan layanan perencanaan indidual kepada para calon pendidik AUD, sehingga calon guru mendapat orientasi perihal aktivitas yang akan dijalani, ini bagai tindakan preventif bagi para calon guru.

Pengambilan data melalui wawancara kelompok memiliki keterbatasan, yakni durasi kurang memadai untuk menggali informasi lebih jauh. Apabila ada penelitian lanjutan mengenai tema pengembangan profesi guru, layanan bimbingan kelompok bisa dilakukan, dan disetiap pertemuan membahas aspek-aspek teori yang dijadikan landasan pembahasan.

\section{Simpulan}

Pengembangan karier bagi guru anak usia dini yang paling mendasar adalah menstandarkan diri dengan kualifikasi profesional sesuai tuntutan peraturan yang berlaku. Guru yang mengawali pekerjaan dengan latar belakang pendidikan yang belum sesuai, pada proses selanjutnya memutuskan untuk melanjutkan pendidikan untuk mencapai kapasitas pendidikan yang sesuai. Proses mendapatkan sertifikasi bagi guru adalah tahapan selanjutnya yang akan diraih. Apabila guru telah memiliki kualifikasi profesional yaitu berlatar belakang pendidikan yang sesuai dan memiliki sertifikat pendidik, maka akan mempermudah guru untuk menjajaki pengembangan karier pada fase selanjutnya. Fase pengembangan karier selanjutnya khususnya bagi guru yang berkeinginan untuk mencapai puncak karier yang ditetapkan guru secara personal. 
Dunia pendidikan anak adalah pembelajaran terbaik bagi para guru, melalui aktivitas pekerjaannya, guru senantiasa terus belajar tentang penanganan anak, mendalami karakteristik anak, metode pembelajaran anak, dan meningkatkan kualitas diri sehingga semakin bertambah ilmu dan keterampilannya. Dunia anak adalah dinamis, bergerak, dan enerjik, guru harus dapat menyesuaikan diri dengan ritme aktivitas anak. Imbalan bagi guru anak usia dini termasuk minim, tetapi kebahagiaan menyaksikan perkembangan anak dan mendapatkan pengalaman pekerjaan dapat menepikan persoalan salary. Dalam bahasa guru, keberhasilan pendidikan anak menyangkut kepuasan bathin. Kepuasan bathin guru dalam pekerjaan didapatkan ketika anak mengalami perubahan dan tugas-tugas perkembangannya terpenuhi.

Studi mengenai pengembangan profesi guru AUD ini penting agar menjadi perhatian bersama bahwa guru AUD harus memiliki kualifikasi memadai, dan bagi guru yang telah berkarier didalamnya dan belum memiliki kualifikasi pendidikan yang memadai agar dibantu untuk berkesempatan melanjutkan studinya. Bila anggaran pemerintah belum dapat membantu program ini, diharapkan pihak kampus memberikan peluang kepada para guru yang belum mengenyam pendidikan tinggi meski dalam jumlah yang terbatas bila dibandingkan dengan keseluruhan jumlah guru yang belum terkualifikasi pendidikannya.

\section{Ucapan Terima Kasih}

Pada kesempatan ini, peneliti ingin mengucapkan terimakasih kepada para pembimbing, kampus UNJ yang memiliki sistem konstruktif bagi para penulis dan peneliti pemula untuk memulai sebuah karya, para partisipan, keluarga dan kerabat peneliti, semoga karya perdana ini adalah pijakan untuk penulisan selanjutnya dalam kapasitas yang lebih baik lagi.

\section{Daftar Rujukan}

Aljurf, Saladin. Linzi J. Kemp \& Paul Williams. (2019). Exploring academic dishonesty in the Middle East: a qualitative analysis of students' perceptions. Studies in Higher Education, 45:7, 1461-1473.

Baedowi, Ahmad. (2015). Potret pendidikan kita. Jakarta : Pustaka Alvabet.

Chin, Wen Chien. (2020). A case study of the use of the Six Thinking Hats to enhance the reflective practice of student teachers in Taiwan. International Journal of Primary, Elementary and Early Years Education. Education 3-13.

Dikilitas, Kenan. Mumford, Simon E. (2020). Preschool English teachers gaining bilingual competencies in a monolingual context. El Sevier journal 0346-251X.

Hamalik, Oemar. (2006). Pendidikan guru berdasarkan pendekatan kompetensi. Jakarta : Bumi Aksara.

Hidayatullah, Afif. 2020. Guru Sugestif?. Jogjakarta : Pancaksara Publisher.

Husien, Latifah.(2017). Profesi keguruan. menjadi guru profesional. Jogjakarta : Pustaka Baru Press.

Ita, Efrida (2020) Pengembangan profesionalitas guru pendidikan anak usia dini (studi pada taman kanak-kanak Ade Irma Mataloko Kabupaten Ngada). Jurnal Ilmiah Pendidikan Citra Bakti. http://jurnalilmiahcitrabakti.ac.id/iil/index.php/jil Volume 07, Nomor 01 Tahun 2020.

Jin, Meilan. Moran, Marry Jane. (2020). Chinese and US Preschool Teachers' Beliefs About Children's Cooperative Problem-Solving During Play. Early Childhood Education Journal.

Musfah, Jeje. (2012). Peningkatan kompetensi guru melalui pelatihan dan sumber belajar teori dan praktik. Jakarta : Prenada Media Group.

Nurfuadi. (2012). Profesionalisme guru. Purwokerta : STAIN Press.

Omdal, Heidi. (2017). Creating teacher capacity in Early Childhood Education and Care institutions implementing an authoritative adult style. J Educ Change (2018) 19:103-129.

Priatna, Nanang. Sukamto, Tito. 2013 . Pengembangan profesi guru. Bandung: Remaja Rosdakarya. 
Rusman. (2014). Model-model pembelajaran mengembangkan profesionalisme guru. Jakarta : Rajagrafindo Persada.

Saud, Udin Syaefudin. (2013). Pengembangan profesi guru. Bandung : Alfabeta.

Soetjipto, Kosasi, Raflis. (2011). Profesi keguruan. Jakarta : Rineka Cipta.

Sugiono. (2009). Metode penelitian pendidikan pendekatan kuantitatif, kualitatif, dan R\&D. Bandung: Alfabeta.

Sujiono, Yuliani Nurani. (2011). Konsep dasar pendidikan anak usia dini. Jakarta: Indeks.

Sukardi. (2011). Metodologi Penelitian Pendidikan. Kompetensi dan praktiknya. Jakarta: Bumi Aksara.

Tim PGRI. (2014) . Pendidikan untuk transformasi bangsa. Jakarta : Kompas Media Nusantara. Wahyudi, Imam. (2012). Mengejar profesionalisme guru. Strategi praktis mewujudkan citra guru profesional. Jakarta : Prestasi Pustakaraya.

\section{Competing interests:}

The authors declare that they have no significant competing financial, professional or personal interests that might have influenced the performance or presentation of the work described in this manuscript. 